\title{
Análise crítica de conformidade de rotulagem de sucos e néctares comercializados no setor varejista de Uberlândia, Minas Gerais
}

Critical compliance analysis of the labeling of juices and nectars marketed in the retail sector of Uberlandia, Minas Gerais

DOI: $10.5935 / 2447-8539.201900010$

PAULA ALVARES BORGES FERREIRA; RAYANE BEZERRA DA SILVA; BRIANY RODRIGUES SILVA; ALINE RODRIGUES GONÇALVES; NATHÁLIA DE FÁTIMA ARAÚJO FONSECA; LAURA CRISTINA TIBILETTI BALIEIRO

e-mail: laura.balieiro@hotmail.com

\section{Resumo}

A rotulagem dos alimentos é essencial para que o consumidor faça escolhas alimentares saudáveis, pois é através das informações da embalagem que ocorre a comunicação da indústria alimentícia com o consumidor. Sendo assim, o objetivo do presente estudo foi analisar de maneira crítica a conformidade da rotulagem de sucos e néctares. Foi realizada uma análise das informações presentes nas embalagens de sucos e néctares comercializados no setor varejista de Uberlândia e se avaliou a conformidade ou não conformidade destes produtos de acordo com a legislação vigente através de quatro check lists, além disso, foi realizada análise de outras variáveis como quantidade de ingredientes e aditivos alimentares, presença de informação nutricional complementar e posição do açúcar na lista de ingredientes. Uma amostra de 109 produtos, sendo eles 56 néctares de frutas e 53 sucos foi analisada. Constatou-se que ainda existem muitas inadequações no cumprimento da legislação, principalmente no que diz respeito às questões nutricionais, e que isso traz diversos prejuízos ao consumidor e uma grande variação na quantidade de ingredientes e aditivos alimentares entre os produtos analisados.

Palavras-chave: Sucos, Rotulagem de alimentos, Legislação sobre alimentos.

\section{Abstract}

Food labeling is essential for the consumer to make healthy food choices because it is through the packaging information that the food industry communicates with the consumer. Therefore, the aim of this study was to analyze critically the conformity of the labeling of juices and nectars. An analysis of the information presented on the juice and nectars packages marketed in the retail sector of Uberlandia was carried out and the conformity or nonconformity of these products was evaluated according to the current legislation as well as the analysis of other variables such as quantity of ingredients and food additives, the presence of complementary nutritional information and the sugar level in the list of ingredients. A sample of 109 products, 56 fruit nectars and 53 juices were analyzed. It has been found that there are still many inadequacies in compliance with the legislation, especially with regards to nutritional issues, bringing a number of harmful issues to the consumer.

Keywords: Juices, Food labeling, Food legislation. 


\section{INTRODUÇÃO}

Nas últimas décadas, o Brasil foi marcado por uma transição nutricional caracterizada pelo aumento no consumo de alimentos ultraprocessados, tanto em domicílio, quanto nas refeições realizadas fora de casa, e pela alteração do perfil de macronutrientes da dieta, como o aumento do consumo de açúcares e de gorduras totais e/ ou saturadas (RINALDI, 2016). Essa transição se relaciona com as mudanças ocorridas no país, no âmbito social, econômico, demográfico e epidemiológico Alberto (2003) e, as principais consequências são a diminuição do consumo de alimentos in natura e minimamente processados, ricos em fibras alimentares, micronutrientes e compostos bioativos (COSTA; 2005, RINALDI; 2016).

Junto a transição nutricional, tem ocorrido também uma transição epidemiológica, marcada pelo aumento crescente da prevalência de doenças crônicas não transmissíveis (DCNT), tais como a obesidade, o diabetes e as doenças cardiovasculares (SILVA; 2008, RINALDI; 2016).

Como relatado, o consumo de alimentos industrializados tem se apresentado em ascensão no mercado consumidor brasileiro, particularmente com relação às bebidas industrializadas, no qual há disponível uma enorme gama de produtos, dentre as quais podem ser citadas os sucos e os néctares (BERTO, 2003).

Por definição, suco é "a bebida não fermentada, não concentrada e não diluída, obtida da fruta madura e sã, ou parte do vegetal de origem, por processamento tecnológico adequado, submetida a tratamento que assegure a sua apresentação e conservação até o momento do consumo. O suco não poderá conter substâncias estranhas à fruta ou parte do vegetal de sua origem, excetuadas as previstas na legislação específica" (BRASIL, 2009).

Já o néctar pode ser definido como "uma bebida não fermentada, obtida da diluição em água potável da parte comestível do vegetal ou de seu extrato, adicionado de açúcares, destinada ao consumo direto" (BRASIL, 2009).

Geralmente, os sucos de frutas são escolhidos pelos consumidores por possuírem vitaminas, minerais e outros componentes importantes para saúde do organismo Perreira (2006), já os néctares por aparentemente terem os mesmos benefícios que o suco de fruta, porém sabe-se que possuem níveis elevados de sódio, açúcar e aditivos (principalmente conservantes), os quais podem contribuir para uma alimentação desbalanceada (FERRARI, 2003).

Bebidas industrializadas à base de frutas podem ser feitas com extratos de frutas e adicionados de açúcar refinado, adoçantes artificiais, conservantes, aromatizantes e outros aditivos alimentares. Portanto, são alimentos ultra processados e, como tais, devem ser evitados (BRASIL, 2014). Ressaltando particularmente a questão do teor de açúcar, sabe-se que os néctares apresentam grande quantidade deste componente e menor porcentagem de fruta em sua composição. Um estudo realizado pelo instituto de defesa do consumidor brasileiro analisou 31 amostras de néctares de sete marcas, e demonstrou que $32 \%$ dos produtos não possuíam o teor de fruta exigido por lei. Além disso, $100 \%$ dos néctares de fruta analisados apresentaram concentração média (entre 5,1 e 12,4g/100g) ou alta $(12,5 \mathrm{~g} / 100 \mathrm{~g})$ de açúcar (INSTITUTO BRASILEIRO DE DEFESA DO CONSUMIDOR, 2014). O consumo excessivo de bebidas industrializadas com alto teor de açúcar é um dos fatores responsáveis pelo aumento de obesidade e de outras DCNT (NOGUEIRA, 2009).

Para que o consumidor obtenha conhecimentos sobre o tipo de bebida que está adquirindo, os sucos e néctares devem informar à população dados de rotulagem de qualidade. Dessa forma, o rótulo deve ser um instrumento que contribui para a orientação de uma alimentação adequada e saudável, prevenção e/ ou tratamento de doenças relacionadas aos maus hábitos alimentares.

Em adição, deverá existir o compromisso de regulamentar e fiscalizar tais produtos, havendo parceria entre indústria e governo (BRASIL, 2013).

Diante do exposto, este trabalho teve como objetivo analisar de maneira crítica a conformidade da rotulagem de sucos e néctares comercializados no setor varejista de Uberlândia, Minas Gerais, e justifica-se pelo direito dos consumidores a informações corretas de rotulagem sobre os produtos que consomem, já que o conhecimento sobre o produto pode definir a escolha dos consumidores na hora da compra.

\section{METODOLOGIA}

Trata-se de um estudo descritivo, que avaliou a conformidade das informações apresentadas nos rótulos de sucos e néctares de frutas comercializados no setor varejista de Uberlândia, Minas Gerais. As marcas analisadas foram escolhidas por serem comumente vendidas nos principais hipermercados da cidade, e totalizaram uma amostra de 109 produtos, sendo eles 56 néctares de frutas e 53 sucos.

A avaliação foi realizada a partir de 4 check-lists que foram elaborados a partir de normas estabelecidas pela legislação vigente, a saber: Instrução Normativa n 42/ 2013 Brasil Brasil (2013); Instrução Normativa n¹2/ 2003 Brasil (2013); RDC 259/ 02 Brasil (2002); RDC $n^{\circ}$ 360/ 03 Brasil (2003). 
O check list da Instrução Normativa n 42/ 2013 era composto por cinco itens: definição de néctares de laranja e uva e quantidade de polpa de fruta; quantidade mínima de 30\% de polpa de suco para frutas não especificadas em regulamento, exceto as de sabor ou acidez forte, que podem ter $20 \%$ de polpa; obrigatoriedade da declaração da quantidade de polpa de fruta no rótulo dos produtos; determinação de que forma a porcentagem de polpa de fruta deve ser declarada no rótulo, sendo em destaque, isolada, no painel principal, com porcentagem em cifra decimal, no tamanho maior que o dobro do tamanho da denominação do produto; e declaração da quantidade de polpa de fruta na lista de ingredientes como informação opcional.

0 check list da Instrução Normativa n 12/ 2003 possuía nove itens: utilização da expressão "pronto para beber", que deve ser utilizada apenas quando o suco for adoçado; definição dos aditivos e coadjuvantes de tecnologia aprovados pela legislação específica dos sucos de frutas que podem ser utilizados na fabricação de sucos e néctares; determinação do teor mínimo de contaminantes de acordo com a legislação específica de sucos; proibição da utilização do termo "Suco integral" para sucos tropicais; obrigatória a declaração, de forma visível e legível, do percentual mínimo da polpa de fruta utilizada; obrigatória a declaração, na lista de ingredientes dos sucos tropicais, os nomes das frutas que o compõem; declaração do termo "adoçado" para o suco tropical pronto para beber; sucos que forem obtidos a partir de sucos concentrados, devem declarar essa origem; e para ser considerado suco tropical, o suco deve conter água e a fruta deve ser de origem tropical.

A RDC $n^{\circ}$ 259/ 02 trata sobre possíveis induções de engano direcionados ao consumidor, e seu check list possuía quatorze itens: não devem haver imagens que causem indução a equívocos; não é permitido atribuir efeitos ou propriedades inexistentes ou não comprovadas ao produto; não é permitido alegação de propriedades nutricionais que sejam intrínsecos a todos os alimentos da mesma natureza ou que sejam adicionados a todos os alimentos com tecnologia de fabricação semelhante; não deve haver destaque de propriedades terapêuticas que alguns componentes ou ingredientes tenham ou possam ter quando consumidos em quantidades diferentes daquelas que se encontram no alimento; não deve haver instruções de consumo do produto para melhora de estado de saúde ou cura de doenças; o lugar de fabricação não deve ser utilizado como propaganda e nem induzir o consumidor a equívocos; quando os alimentos forem fabricados segundo tecnologias de locais geográficos específicos, para obter propriedades sensoriais semelhantes, a denominação do alimento deve declarar a expressão "tipo", com visibilidade; normas para denominação de venda do produto; normas para a lista de ingredientes; informações obrigatórias para estabelecer a origem do produto; normas para alimentos importados; obrigatoriedade da expressão do lote na embalagem, e como deve ser feita; e como deve ser declarado o prazo de validade.

A RDC $n^{\circ}$ 360/ 03 refere-se a rotulagem nutricional obrigatória. O check list possuía dezessete itens: obrigatoriedade da declaração de 7 nutrientes na informação nutricional; nutrientes que sejam declarados, além dos obrigatórios, deve haver declaração da quantidade; declaração de propriedades nutricionais sobre o tipo de carboidratos, gorduras, ácidos graxos ou colesterol, deve conter indicação da quantidade; informação nutricional deve estar agrupada, em forma de tabela, e que se não houver espaço para isso, pode ser feita de forma linear; declaração do valor energético e dos nutrientes deve estar em forma numérica; informação nutricional deve estar no idioma do país de consumo; informações nutricionais devem estar em contraste com a cor de fundo da embalagem, em lugar visível e de forma legível; as unidades de medida devem ser utilizadas na rotulagem e a quantidade de cifras de acordo com o valor; os percentuais e o valor energético devem estar em números inteiros; deve haver a expressão da informação nutricional por porção e medida caseira correspondente, ou em $100 \mathrm{~g}$ ou ml; obrigatória a declaração da expressão "Seus valores diários podem ser maiores ou menores dependendo de suas necessidades energéticas"; como deve ser realizada a declaração da quantidade de açucares, polióis, gorduras e colesterol; e quando for declarada informação nutricional facultativamente, a mesma deve seguir a legislação.

Para cada item dos check lists avaliados, os sucos e néctares de frutas foram classificados em três categorias: "conforme", quando a rotulagem do alimento estivesse de acordo com a legislação vigente, "não conforme" quando a rotulagem estivesse em desacordo com a legislação vigente, e por último, "não se aplica" quando o alimento não se enquadrava no item em questão. Além disso, foram avaliados também a lista de ingredientes, observando o número de ingredientes, o tipo de açúcar e a posição na lista de ingredientes, quais e quantos aditivos foram utilizados, a quantidade de calorias por porção, e a informação nutricional complementar de cada produto analisado.

A estatística consistiu na análise descritiva, verificando a frequência de conformidade e não conformidade dos itens de cada check list, e os resultados foram apresentados em porcentagem. Os dados coletados fora dos check lists, foram apresentados em média e desvio padrão ou porcentagem e número. 


\section{RESULTADOS E DISCUSSÃO}

Foram analisados 109 produtos, dentre eles 56 néctares de fruta e 53 sucos, de diversas marcas e sabores. Foram avaliadas variáveis da composição desses produtos, apresentadas na Tabela 1.

Após observar a quantidade de ingredientes dos produtos, os néctares de fruta apresentaram média de 8 ingredientes, um número maior quando comparado a média de ingredientes dos sucos. Ressalta-se que discrepância se deve a adição excessiva de aditivos alimentares nos néctares de fruta.
Os sucos apresentaram média de utilização de apenas 1 aditivo, enquanto os néctares de 5 aditivos. 0 uso de aditivos na fabricação de alimentos tem sido cada vez maior na alimentação moderna devido à capacidade de manter a qualidade e aumentar a validade dos alimentos Gouveia (2006), entretanto, muitos estudos têm demonstrado reações adversas ao consumo de aditivos, a curto ou longo prazo, desencadeando alergias, possíveis alterações neoplásicas e comportamentais (POLÔNIO, 2009).

Tabela 1 - Variáveis analisadas na rotulagem de sucos e néctares de fruta.

\begin{tabular}{|c|c|c|}
\hline \multicolumn{2}{|c|}{ Variáveis } & \multirow{2}{*}{$\frac{\text { Média } \pm \text { DP ou n (\%) }}{8,25 \pm 1,97}$} \\
\hline \multirow{4}{*}{ Néctares de fruta } & Número de ingredientes & \\
\hline & Número de aditivos & $4,7 \pm 2,01$ \\
\hline & Valor energético (kcal) & $93 \mathrm{kcal} \pm 28,7$ \\
\hline & Existência de informação nutricional & $83 \%(n=46)$ \\
\hline \multirow{6}{*}{ Posição do açúcar } & $2^{\mathrm{a}}$ posição & $37,5 \%(n=21)$ \\
\hline & $3^{\circ}$ posição & $52 \%(n=29)$ \\
\hline & $4^{\circ}$ posição & $1,7 \%(n=1)$ \\
\hline & $7^{0}$ posição & $5,4 \%(n=3)$ \\
\hline & $8^{\circ}$ posição & $1,7 \%(n=1)$ \\
\hline & $9^{\circ}$ posição & $1,7 \%(n=1)$ \\
\hline \multirow{4}{*}{ Sucos } & Número de ingredientes & $2,9 \pm 2,63$ \\
\hline & Número de aditivos & $1 \pm 1,30$ \\
\hline & Valor energético & $110 \mathrm{kcal} \pm 34,4$ \\
\hline & Existência de informação nutricional & $23 \%(n=12)$ \\
\hline \multirow{3}{*}{ Posição do açúcar } & Não contém açúcar & $94,4 \%(n=50)$ \\
\hline & $2^{\mathrm{a}}$ posição & $3,7 \%(n=2)$ \\
\hline & $3^{\circ}$ posição & $1,9 \%(n=1)$ \\
\hline
\end{tabular}

Sobre a presença de informação nutricional complementar, $83 \%$ dos néctares de fruta apresentavam essas informações, enquanto os sucos, apenas 23\%. Atualmente a indústria alimentícia tem utilizado as embalagens como vendedores mudos, transmitindo mensagens visuais diretas que despertam no consumidor o desejo para compra e utilização do produto Elias (2009), dessa forma, por ser um produto com menos porcentagem de fruta, e consequentemente menos qualidade em questão nutricional se comparado aos sucos, os néctares apresentam mais informações nutricionais complementares para atrair o consumidor.
A quantidade de açúcar presente nos produtos foi avaliada pela posição na lista de ingredientes, já que esta deve ser apresentada em ordem decrescente de proporção Anvisa (2002). Noventa e quatro por cento dos sucos não possuem adição de açúcar, enquanto 89,5\% dos néctares apresenta açúcar como segundo ou terceiro ingrediente na lista. Essas altas concentrações de açúcar aumentam o consumo diário de açúcar do consumidor, sem que ele tenha conhecimento, pois por ser uma bebida derivada de fruta, e a maior parte dos consumidores não saber diferenciar sucos e néctares Ferrari (2008), existe a associação do consumo dos 
néctares com hábito alimentar saudável, o que acaba não sendo real.

Check lists podem ser utilizados para verificação do cumprimento de leis, realização de atividades a serem cumpridas, verificação de materiais e estoque, e têm o objetivo de garantir a conferência de todos os passos essenciais da atividade em questão (ALBERTO, 2014). Os resultados das análises dos itens do check list da Instrução Normativa n 42/ 2013 estão apresentados no Gráfico 1.

Gráfico 1 - Quantidade de sucos e néctares em não conformidade com o check list da Instrução Normativa n 42/ 2013

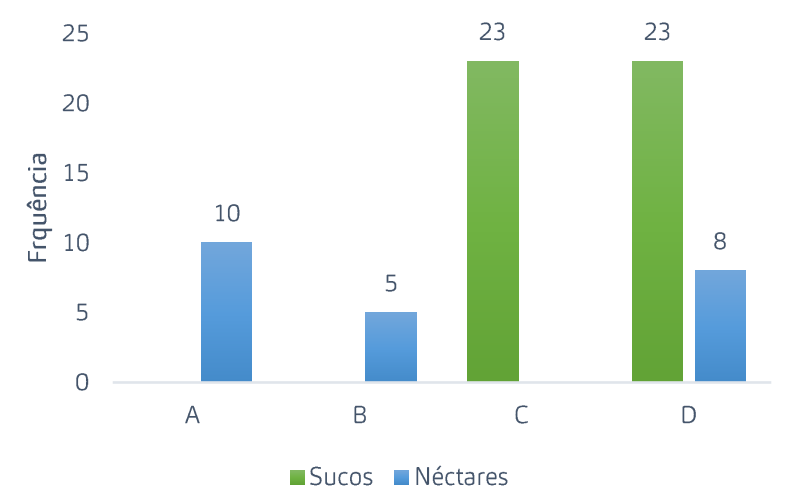

Legenda: A - Obrigatoriedade de 50\% de polpa de fruta nos néctares de laranja e uva. Obrigatoriedade de 30\% de polpa de fruta nos sabores de néctares não estabelecidos na legislação específica, exceto os de sabor ou acidez forte, que podem ter até $20 \%$. Declaração obrigatória da quantidade de polpa de fruta no rótulo. D - Obrigatoriedade de a declaração da quantidade de polpa estar no painel principal do rótulo, em destaque e com uma cifra decimal.

Os produtos que apresentam porcentagem de fruta abaixo do permitido contribuem para piora na alimentação dos consumidores no que diz respeito a questão nutricional, pelo fato de que muitos deles não sabem a diferença entre suco e néctar de fruta, e assim optam pelo néctar como uma escolha saudável, como já dito anteriormente, sem o conhecimento da baixa porcentagem de fruta presente no produto (FERRAREZI, 2008).

A falta de declaração da quantidade de polpa de fruta utilizada da produção de sucos e néctares é bastante prejudicial ao consumidor, já que é através das informações nutricionais declaradas no rótulo, que ele pode fazer escolhas alimentares mais saudáveis (LIMA 2003).

O check list da RDC $n^{\circ}$ 259/ 02 possuía quatorze itens, e três deles apresentaram inconformidade relevante. 0 item que define que não é permitido declarar propriedades nutricionais próprias a todos os alimentos de mesma natureza, apresentou 50\% $(n=28)$ de não conformidade dos néctares e 17\% ( $n=9)$ dos sucos. E o item que determina que não é permitido declarar componentes que sejam adicionados como ingredientes em todos os alimentos com tecnologia de fabricação semelhante, teve o mesmo resultado que o item anterior. Com o aumento da preocupação dos consumidores com a relação alimentação-saúdedoença, as indústrias alimentícias têm investido cada vez mais em atingir o novo perfil do consumidor, que deseja alimentos equilibrados do ponto de vista nutricional e fáceis e rápidos de consumir, assim se utilizam de diversas ferramentas de marketing para conquistar o cliente, portanto faz se necessário estar atento a veracidade das imagens e informações veiculadas como propaganda, pois a mídia tem exercido papel fundamental na formação de novos hábitos alimentares sociais (MARINS, 2011).

0 check list da RDC $n^{\circ}$ 360/ 03 possuía dezesseis itens, e apenas um item apresentou não conformidade, de $4 \%$ $(n=2)$ para os sucos. 0 item define que é obrigatório expressar a quantidade de qualquer nutriente que se faça declaração de propriedade nutricional. 0 cumprimento deste item é essencial para que o consumidor possa fazer comparação entre produtos similares e escolher entre estes, de acordo com a quantidade maior de um ou outro nutriente, o que mais se adequada a sua necessidade no momento (ANVISA, 2008).

\section{CONCLUSÕES}

Diante do exposto, foi possível perceber que ainda existem muitas inadequações nos rótulos dos produtos, principalmente no que tange as questões nutricionais. $E$ que, por diversas vezes o consumidor acaba sendo induzido a equívocos e levando a escolhas ruins sem que haja conhecimento do valor nutricional do produto. Percebe-se a necessidade de uma preocupação maior dos órgãos públicos que regulamentam os rótulos, para que haja uma fiscalização mais rígida. Assim como também, se faz necessário que haja educação dos consumidores sobre a leitura desses rótulos, para que o consumidor esteja ciente na hora de fazer suas escolhas alimentares.

\section{REFERÊNCIAS}

ANVISA - Agência Nacional de Vigilância Sanitária. Gerência Geral de Alimentos. Universidade de Brasília, Departamento de Nutrição. Manual de orientação aos consumidores: educação para o consumo saudável. Brasília: Ministério da Saúde; 2008. Disponível em:

http://portal.anvisa.gov.br/documents/33916/396679/manu al consumidor.pdf/e31144d3-0207-4a37-9b3b-

e4638d48934b. Acesso em: 05 jul. 2019. 
BERTO, D. Bebidas não alcoólicas: apelo 'saudável'

impulsiona consumo. Food Ingredients, n.24, p. 32-34, 2003.

BRASIL. Decreto n 6.871, de 4 de junho de 2009.

Disponível em:

http://www.agricultura.gov.br/assuntos/vigilanciaagropecuaria/ivegetal/bebidas-arquivos/decreto-no-6-871de-4-de-junho-de-2009.doc/view. Acesso em: 12 jul.2019

BRASIL. Ministério da agricultura, pecuária e abastecimento. Decreto $n^{\circ}$ 6.871, de 4 de junho de 2009. Diário Oficial da União; Poder Executivo, Brasília, DF, 4 de junho de 2009. Disponível em:

http://www.agricultura.gov.br/assuntos/vigilanciaagropecuaria/ivegetal/bebidas-arquivos/decreto-no-6-871de-4-de-junho-de-2009.doc/view. Acesso em: 11 jul.2019.

BRASIL. Ministério da agricultura, pecuária e abastecimento. Instrução normativa $n^{\circ} \mathbf{1 2}$, de 4 de setembro de 2003. Diário Oficial da União; Poder Executivo, Brasília, DF, 4 de setembro de 2003. Disponível em:

http://www.agricultura.gov.br/assuntos/inspecao/produtosvegetal/legislacao-1/biblioteca-de-normas-vinhos-ebebidas/instrucao-normativa-no-12-de-4-de-setembro-de2003.pdf/view. Acesso em: 10 jul.2019.

BRASIL. Ministério da agricultura, pecuária e abastecimento. Instrução normativa $n^{\circ}$ 42, de 11 de setembro de 2013. Diário Oficial da União; Poder Executivo, Brasília, DF, 11 de setembro de 2013. Disponível em:

http://www.in.gov.br/materia/-

Lasset publisher/Kujrw0TZC2Mb/content/id/31054165/do1 2013-09-12-instrucao-normativa-n-42-de-11-de-setembrode-2013-31054161. Acesso em: 10 jul.2019.

BRASIL. Ministério da Saúde. As doenças transmissíveis no Brasil: tendências e novos desafios para o Sistema Único de Saúde. In: Ministério da Saúde. Saúde Brasil 2008: 20 anos de Sistema Único de Saúde. $1^{\circ}$ ed. Brasília: 2009, p.337. Disponível em:

http://bvsms.saude.gov.br/bvs/publicacoes/saude brasil 20 08.pdf. Acesso em: 20 jul.2019.

BRASIL, Ministério da Saúde. Guia Alimentar para população brasileira promovendo a alimentação saudável. Normas e manuais técnicos: Brasília, 2014. Disponível em: http://bvsms.saude.gov.br/bvs/publicacoes/guia alimentar populacao brasileira 2008.pdf. Acesso em: 18 jul.2019.

BRASIL. Ministério da Saúde. Secretaria de Vigilância Sanitária. Regulamento técnico sobre rotulagem de alimentos embalados. Resolução - RDC $n^{\circ} 259$, de 20 de setembro de 2002. Diário Oficial da União; Poder Executivo, Brasília, DF, 23 set. 2002. Disponível em:

http://www.agricultura.gov.br/assuntos/inspecao/produtosvegetal/legislacao-1/biblioteca-de-normas-vinhos-ebebidas/resolucao-rdc-no-259-de-20-de-setembro-de2002.pdf/view. Acesso em: 04 jul.2019

BRASIL. Ministério da Saúde. Secretaria de Vigilância Sanitária. Regulamento técnico sobre rotulagem de alimentos embalados. Resolução - RDC $n^{\circ}$ 360, de 23 de dezembro de 2003. Diário Oficial da União; Poder Executivo, Brasília, DF, 26 dez.2003. Disponível em: http://portal.anvisa.gov.br/documents/33880/2568070/res0 $36023 \quad 12$ 2003.pdf/5d4fc713-9c66-4512-b3c1afee57e7d9bc. Acesso em: 07 jul.2019.

COSTA.L. R.B; SICHIERI. R; PONTES.N.S; MONTEIRO. C.A. Disponibilidade domiciliar de alimentos no Brasil: distribuição e evolução (1974-2003). Rev Saúde Pública. 2005;39(4):530-40.

FERRAREZI, A.C. Interpretação do consumidor, avaliação da intenção de compra e das características físico-químicas do néctar e do suco de laranja pronto para beber. 2008.104 f. Dissertação (Mestrado) - Universidade Estadual Paulista, Faculdade de Ciências Farmacêuticas, 2008.

FERRARI, C.C.; SOARES, L.M. Concentrações de sódio em bebidas carbonatadas nacionais. Revista Ciência e Tecnologia de Alimentos. 23(3): 414-417, 2003.

GOUVEIA, F. Indústria de alimentos: no caminho da inovação e de novos produtos. Inovação Uniemp, Campinas, v. 2, n. 5, dic. 2006.

INSTITUTO BRASILEIRO DE DEFESA DO CONSUMIDOR. Falta fruta na caixinha. Revista do IDEC n0184. Fevereiro, 2014.

LIMA, A.; GUERRA, N. B.; LIRA, B. F. Evolução da legislação brasileira sobre rotulagem de alimentos e bebidas embalados, e sua função educativa para promoção da saúde. Revista Higiene Alimentar. 2003; 17(110):12-7.

MARINS. B. R; ARAUJO. I. S; JACOB. S. C. Food advertising: advice or merely stimulation of consumption? Ciência e Saúde Coletiva, 2011; 16(9): 3873-3882.

NOGUEIRA, F. A.B; SICHIERI, R. Associação entre consumo de refrigerantes, sucos e leite, com o índice de massa corporal em escolares da rede pública de Niterói, Rio de Janeiro, Brasil. Caderno de Saúde Pública [online]. 2009, vol.25, n.12, pp.2715-2724. Disponivel em:

http://www.scielo.br/scielo.php?pid=S0102-

$311 \times 2009001200018 \&$ script=sci abstract\&tlng=pt. Acesso em: 19 jul.2019.

PERREIRA, B. Processamento agrega valor. Frutas e Derivados- Publicação Trimestral do IBRAF. São Paulo: n 1, ed.3, p.19-26, setembro de 2006.

POLÔNIO, M. L. T.; PERES, F. Consumo de aditivos alimentares e efeitos à saúde: desafios para a saúde pública brasileira. Cadernos de Saúde Pública, Rio de Janeiro, v. 25, п. 8, p.1653-1666, 2009

PONTES, E. et al. Orientação nutricional de crianças e adolescentes e os novos padrões de consumo: propagandas, embalagens e rótulos. Revista Paulista de Pediatria, 27 de março de 2009.

RINALDI, A. E. M.; CONDE, W. L. Transição Nutricional. In: DASILVA, C. O.; DE-SOUZA A.D.; PASCOAL, G.B.; SOARES, L.P. Segurança alimentar e nutricional. $1^{\circ}$ edição. Rio de Janeiro: Editora Rubio, 2016. 
SIMPÓSIO DE EXCELÊNCIA EM GESTÃO E TECNOLOGIA

(SEGET), 2014, Rio de Janeiro. Uma proposta de aplicação de checklists de qualidade como mecanismo de melhoria de produtos de trabalho em disciplinas do eixo de Engenharia de software. Resende, RJ, 2014. Disponível em: https://www.researchgate.net/publication/320130742 Uma Proposta de Aplicacao de Checklists de Qualidade como Mecanismo de Melhoria de Produtos de Trabalho em D isciplinas do Eixo de Engenharia de Software. Acesso em: 02 jul. 2019. 